\title{
MISINTERPRETATION OF THE STRATEGIC SIGNIFICANCE OF COST DRIVER ANALYSIS: EVIDENCE FROM MANAGEMENT ACCOUNTING THEORY AND PRACTICE
}

This paper traces the development of cost driver theory in the Strategy literature and reflects on misinterpretations of the strategic significance of the theory in related academic disciplines, notably Management Accounting.

Management Accounting has largely been responsible for informing costing practice in a wide range of organizational settings. The paper con- siders one such application - i.e. the case of the Higher Education Funding Council's (HEFC) costing and pricing initiative for UK universities.

The project was completed just under five years ago, although details of implementation are still ongoing, to a degree. The systems in place incorporate most of the theoretical flaws outlined in this paper. Rather than providing cost driver analysis to 
aid the strategic management process in universities, the system appears to represent little more than a compliance and reporting framework between university central administrations and the funding provider, HEFC.

\section{Introduction}

The need for better cost information relating to products, services, customers and competitors has often been triggered by changes in the competitive environment in which organizations operate. The changes have almost invariably been characterized by increasingly competitive, challenging and deregulated environments. In such circumstances managers have a greater need for information to improve the quality and efficiency of the activities they perform and to better understand those of their competitors. Given the huge debt burden currently faced by the UK and other governments worldwide, these issues are becoming acute, particularly for publicly funded organizations.

The paper begins with the development of cost driver theory in the Strategy literature. It then proceeds to consider how the theory has been interpreted in the field of Management Accounting, and finally the degree to which it is has been incorporated into management practice in the specific context of the Higher Education Funding Council's costing and pricing initiative for UK universities.

\section{The development of cost driver theory}

Arguably the first use of the term «cost drivers» was by Michael Porter [10]. Prior to this, both in the Management Accounting and Economics literature, analysis of cost behaviour tended to be restricted to scale and, more recently, experience effects. Both scale and experience fit into the cost behaviour model normally found in Economics, whereby costs for the whole firm are classified as either fixed or variable with respect to volume of output or activity. Volume has traditionally been the only recognized cost driver, to use Porter's terminology.

Porter identifies a whole range of cost drivers impacting on businesses, in addition to scale and experience, which he considers to be fundamental to the formulation of competitive strategy, either through cost leadership or differentiation. These include: linkages through the value chain; interrelationships; integration; timing; policies; location; institutional factors and, more recently, complexity.

«The behaviour of a firm's costs and its relative cost position stem from the value activities the firm performs in competing in an industry. A meaningful cost analysis, therefore, examines costs within these activities and not the costs of the firm as a whole. Each value activity has its own cost structure and the behaviour of its costs may be affected by linkages and interrelationships with other activities both within and outside the firm» [10].

Ignoring multiple cost drivers and/or attempting to bundle them together into an overall average total cost curve as is the case in Economics, can be, at best, unproductive and potentially dangerous. For a documented case study of how ignoring cost drivers beyond scale of output can seriously disadvantage the competitive position of a firm see «Adolph Coors in the Brewing Industry» in Ghemawat, P. [6]. In chapter 3 of his book Ghemawat also provides an illuminating discussion of the way in which intelligent use of relative cost driver analysis can inform a firm's understanding of its own competitive position vis-à-vis its competitors. Generally it can be argued that competitive strategy must always be concerned with a firm's relative position, focusing as much on the external competitive landscape as internally on its own activities, costs and resources.

Notwithstanding these important developments in strategic thinking about costs and cost drivers, their impact appears to have been either largely ignored, as seems to be the case in the Economics of the Firm, or, to some degree at least, misinterpreted in the broader Management and, in particular, Management Accounting literatures.

\section{Cost driver analysis in Economics}

Both in terms of standard text books and even in post-graduate masters programmes with which the author is familiar, cost analysis is largely restricted to the firm's overall short run average total cost curve and its relatively limited implications for protection from, or exposure to, competitive forces. Some might argue that Williamson's work on transaction costs is developmental. However this mainly addresses governance structures in the context of choices facing firms between markets and hierarchies as the most effective means of organization. Therefore in comparison with work in Management Accounting, Economics appears to have had relatively little impact on organizational practice.

\section{Recent developments in cost theory in Management Accounting}

Arguably one of the most significant contributions to Management Accounting in the last twenty 
years or so has been the development of Activity Based Cost (ABC) theory. This is largely attributable to Robert Kaplan and Robin Cooper's research at Harvard Business School during the 1990s.

Central to ABC theory is a recognition of multiple cost drivers operating at any one time in many different types of organization, with many costs not driven by volume of output or activity. What is nevertheless somewhat puzzling is that in none of their publications or case studies do the authors appear to make any reference to or direct use of Porter's seminal work on cost drivers. It is the author's view that this conscious or unconscious ignoring of Porter's writing on competitive strategy has contributed to subsequent problems and difficulties in $\mathrm{ABC}$ theory and practice. In order to better understand the significance of this we need to look at $\mathrm{ABC}$ in its organizational context. To this end consideration will be given to the development of an $\mathrm{ABC}$ system for UK universities, instigated by the Higher Education Funding Council (HEFC).

\section{The introduction of $\mathrm{ABC}$ in UK Universities}

There has been increasing interest in costing in Higher Education (HE) institutions commencing with the Costing Guidelines for HE [13] produced by the Joint Higher Education Funding Councils [14] — see Westbury, D. [12]; and culminating in the Deloitte review of the joint costing and pricing steering group in 2005 .

There is evidence, however, of misinterpretation of relevant theory relating to university cost systems in the relevant UK literature, which itself appears mainly to inform the Funding Councils' report. Additionally, and of equal importance, insufficient consideration has been given to the relationship between cost system design and implementation and institutional strategy, structure.

With reference to service organizations, Kaplan and Cooper observe that: «<...> lack of accurate information about products and customers was not a concern for many decades because most service companies operated in benign, non-competitive markets lacking strong competitive pressures, managers of service organizations had little demand for cost information about products, customers and processes» [8].

Kaplan's contention that «one cost system is not enough» [7], historically only really applied to manufacturing firms. Service organizations, on the other hand, operated for decades without any cost systems whatsoever. Financial control was restricted to budgetary control of responsibility centers, with little, if any, use of flexible budgets, since $"<\ldots>$ almost all of a Service company's costs come from resources committed in advance of use» [8].

This characterization of service organizations is also an accurate portrayal of UK Universities. Increasing competition should lead to an increase in interest in costs, as cost information will become necessary for three broad classes of managerial decision;

— «Managing products and customers,

- Configuring the customer service delivery chain, and

- Budgeting the organization's supply of resources» [8].

In terms of products and services, service organizations typically provide a highly diverse set of offerings. This also applies to UK Universities and to faculties within them. Diversity and complexity dictate the need for better cost information.

\section{$\mathrm{ABC}$ theory and its misinterpretation in the UK literature}

Two related aspects of $\mathrm{ABC}$ theory in particular seem to have been poorly understood in the UK University/ABC literature. These are:

1. Cost hierarchies of activities;

2. The important distinction between the cost of resources used as measured by $\mathrm{ABC}$ models, and the cost of resources supplied as reported by conventional financial systems, and how this distinction helps to identify excess capacity.

\section{Cost hierarchies of activities}

Cooper provides the following definition of an $\mathrm{ABC}$ system: «An $\mathrm{ABC}$ system identifies and then classifies the major activities of a facility's production process into one of the following four categories: unit level, batch level, product level and facility level activities. Costs in the first three categories of activities are assigned to products using bases (i.e. cost drivers) that capture the underlying behaviour of the costs that are being assigned. The costs of facility level activities, however, are treated as period costs or allocated to products in some arbitrary manner» [3].

The key point in this is that if inappropriate drivers are used to assign cost of products, customers or services, then this results in cost distortion. Traditional absorption cost systems allocate all costs, other than direct, using unit level drivers only, 
and hence effectively guarantee cost distortion in all but single product firms.

Equally important is the fact that Kaplan and Cooper now recognize that there will always be some organizational costs which cannot be assigned to products, services or customers other than arbitrarily, and if this is done then some degree of cost distortion will ensue. Cooper calls these facility sustaining costs, and it is possible to interpret these via Porter's value chain as support activity costs, as opposed to primary activity costs. A product, customer or service profit will be the difference between attributable revenues and all primary activity assigned costs and this can be thought of as an $\mathrm{ABC}$ contribution, before deduction of other nonassignable facility level costs.

«An ABC model should always attempt to drive costs as far down in the organization as it can, but no farther. If an activity is truly sustaining at a given level, no meaningful driver can be found that captures a cause-and-effect relation between the activity and a cost object at the next level... little to no benefit, for decisions on operational improvements, pricing, product mix, and customer relationships is gained from allocating a unit's sustaining expenses down to individual products, services and customers» [8].

In their development of overhead recovery models at the University of Manchester, Scapens et al [11] admit, briefly in passing, that theirs is not an $A B C$ system proper, nevertheless they use $A B C$ terminology extensively (cost drivers, for example) and even make seemingly spurious distinctions between certain types of central costs (e.g. museum and art gallery costs) and state that these cannot be allocated by their three chosen «drivers» (space, students, staff). They provide no attempt at the application of activity costs hierarchy analysis to arrive at the drivers used. Their analysis is also limited to central overhead allocation to faculties, with no consideration of intra-faculty cost driver analysis which would be much more useful for the types of decision faculty managers will increasingly face.

Mitchell [9] picks up this point, but also displays some confusion with ABC: "If we accept the inevitability of devolution, at least for the foreseeable future, then it would appear we also have to accept that $\mathrm{ABC}$ in a University will be normally of greater interest to schools than to central management».

We agree. The issue of devolved management will be considered further below. But he goes on to say: «This is very much against the centralist ethos of $\mathrm{ABC}$, where knowledge of all organizational activities is instigated and distilled into product cost»» [9].

We do not agree, for the theoretical reasons outlined above.

\section{Resource usage and resource supply}

«Service companies in general are ideal candidates for activity-based costing, even more than manufacturing companies. Service companies must supply virtually all their resources in advance. The resources provide the capacity to perform work for customers during each period. Fluctuations in the demand by individual products and customers for the activities performed during the period by these resources do not influence short-term spending to supply the resources» [8].

In effect marginal cost for service companies is effectively close to zero, hence any attempts to apply traditional relevant cost analysis or contribution theory based on the notion of variable (marginal) costs are doomed to failure or will produce spurious results and analysis. For service companies there is almost complete separation between decisions to incur costs and the decisions by customers that generate demand for resources. Kaplan and Cooper provide the following fundamental equation to reflect the above:

Traditional financial accounting systems accurately measure the left hand side of the equation, but they are incapable of providing any insight into the split on the right hand side. It is $\mathrm{ABC}$ systems which help to measure cost of resources used correctly.

«Measuring, creating and managing unused capacity are the heart of activity-based costing» [8].

Section 5.3.3 of the Joint Funding Council's report on Costing in Higher Education makes the following key points:

- «All costs are included and the model reconciles with the institution's published financial accounts (or a recognizable financial statement);

- the costs of using capital assets are reflected;

- there is a consistent classification of costs as direct or indirect;

— indirect costs are apportioned over all the main activities of the institution» [12].

These comments clearly display a lack of awareness of relevant theory. Further evidence of this is provided at the end of Appendix AL of the same report: «The easiest way to ensure that all costs are included is to reconcile the financial and other statistical information used in costing to the audited 
accounts of the institution. Any reasonable cost study should be tied to or reconciled to the financial statements so that:

— the cost information has credibility;

— costs are not lost in the cost analysis;

- there is no duplication of costs;

- the information is reliable;

- the cost information can be documented and audited if required $<\ldots>$ » [12].

A top-down auditing/financial accounting and compliance orientation is highly evident here. It is at odds with relevant theory and is highly unlikely to provide relevant information for managers of university faculties and schools, the latter being the equivalent of strategic business units in commercial enterprises, with the consequence that managers have little or no understanding of where spare capacity resides, at least via the system.

\section{Strategy and structure in universities «top- down» versus «bottom-up» orientations to analysis and implementation of $\mathrm{ABC}$ systems}

Most of the UK literature and costing developments (e.g. at Manchester) appear to possess a «top-down» orientation. For example Manchester University developed a cost system for allocating central overhead to faculties Scapens et al (1994). Despite protestations to the contrary [12], also exhibits such a «top-down» perspective.

However, most documented case studies of ABC implementations were based on business units or divisions of larger organizations, e.g. John Deere Component Works, Hewlett Packard and Tektonix.

The component works, in fact, was pushed towards the need for $\mathrm{ABC}$ precisely because the John Deere group had moved to a divisional structure in the mid 1980s, thus exposing the component works to a much more competitive and hostile environment which required much better cost information to product pricing. The new system was designed only for the division in order to support its strategic management in the new, highly competitive, environment to which it was now exposed. See «John Deere component works» case study in Cooper and Kaplan [4].

As well as Divisions/Business Units developing systems for themselves, the initiatives for many documented $\mathrm{ABC}$ developments were often not initiated by the accounting/finance function but by engineers, production managers, nurse managers etc. Indeed the strong message from many documented $\mathrm{ABC}$ implementations is that accountants did not have sufficient understanding of what actually goes on at the «shop-floor» or front-line level of the operation in order to develop suitable $A B C$ systems for managers. Note Cooper [2] in this context.

The UK literature surveyed makes hardly any references to specific $\mathrm{ABC}$ cases - whereas Kaplan informs us the whole theory of $\mathrm{ABC}$ was essentially developed through cases.

It is unlikely, a priori, that the central accounting function in a University would be any better placed to understand the academic activities taking place at faculty/departmental level. The highly specialist and focused nature of academic teaching and research would probably make it exceedingly difficult for central administrators to understand how this works, what activities should take priority, what adds value and what detracts from value etc.

For a review of some of the issues in this context, see Angluin and Scapens [1], which deals with a «bottom-up» perspective on how Universities allocate resources to academic departments.

\section{Commentary}

The overall process of the implementation of the new costing framework in UK universities was completed just over 5 years ago. It incorporates the theoretical flaws outlined in this paper and provides little more than a compliance and reporting framework between university central administrations and the funding provider, HEFC.

It is evident that this costing initiative in the higher education sector was based on fundamental misconceptions of several key aspects of $\mathrm{ABC}$ theory, as developed by Kaplan and Cooper.

Kaplan's adage that one cost system is not enough applies to the University sector. This is because full cost information is required for accountability purposes, akin to the way in which financial reporting information is necessary for compliance purposes in the private sector, both for service and non-service (manufacturing) organizations. However such full cost information, it is suggested, will not be much use for the three broad classes of internal managerial decision referred to earlier. Confusing compliance driven full cost information with internal activity related decision support cost information will be just as detrimental for a University as to any other service organization facing the threat of an increasingly competitive and hostile environment. 
However had the development adhered faithfully to $\mathrm{ABC}$ theory, it is still unlikely that the systems would be providing much of the necessary information for strategic management within universities and, more importantly, in the university «business units», i.e. academic faculties and business schools.

The explanation for this lies in the fact that even Cooper and Kaplan's orientation, in terms of system design, tends to be overwhelmingly internally focused. Well designed ABC systems tend, generally, only to address one of Porter's categories of cost drivers - i. e. organizational complexity.

Additionally the whole area of relative cost analysis, whereby attempt is made to compare an organization's value chain and associated costs with that of its competitors, appears to have been largely ignored. Yet strategists such as Porter and Ghemawat would probably argue that these are precisely the areas where relevant cost driver analysis would be most useful to organizations in their efforts to develop and maintain competitive advantage.

The cost systems now in place in universities do not address such strategic issues. They are essentially founded on the needs for compliance and external reporting to funding providers, rather than the provision of decision relevant information for managers. That they are considered to be ABC systems further adds to confusion.

It is hardly surprising that in response to an opinion survey concerning the four main aims of the initiative, less than $50 \%$ of respondents thought the aims had been achieved. Deloitte consulting report to HEFC [5].

\section{References}

1. Angluin, D. \& Scapens, R. W. (2000). «Transparency, Accounting Knowledge and Perceived Fairness in UK Universities Resource Allocation: Results from a Survey of Accounting and Finance», British Accounting Review, Volume 32 Number 1, March.

2. Cooper, R. (1996). «The Changing Practice of Management Accounting», Management Accounting, March.

3. Cooper, R. (1990). «Cost Classification in Unit-Based and Activity-Based Manufacturing Cost Systems», Journal of Cost Management Fall.

4. Cooper, R. \& Kaplan, R. S. (1998) «The Design of Cost Management Systems» Prentice Hall.

5. Deloitte Consulting (2005) «Review of the Joint Costing and Pricing Steering Group: August 2002 to July 2005. HEFC (Higher Education Funding Council).

6. Ghemawat, P. (1999) «Strategy and the Business Landscape- Text and Cases» Addison-Wesley Longman.

7. Kaplan R. S. (1988). "One Cost System Isn't Enough", Harvard Business Review, January - February.

8. Kaplan, R. S. \& Cooper R. (1998) Cost \& Effect - Using Integrated Cost Systems to Drive Profitability and Performance, Harvard Business School Press.

9. Mitchell, M. (1996). "Activity-Based Costing in UK Universities», Public Money and Management, January March.

10. Porter, M. E. (1985) «Competitive Advantage. Creating and Sustaining Superior Performance». The Free Press.

11. Scapens, R. W., Ormston, A. L. \& Arnold, J. (1994). «The Development of Overhead Recovery Models at the University of Manchester», In Management Accounting in Universities, CIMA.

12. Westbury D. (1997). «Management Information for Decision Making: Costing Guidelines for Higher Education Institutions». Higher Education Funding Councils for Scotland, England and Wales, July.

\section{UDC 336.6}

keywords: cost driver, cost driver theory, higher education 